\title{
Globalization through Community-Based Projects: Enhancing Civic Attitudes and Competence Skills in Undergraduates
}

\author{
Mah Ngee Lee, Pei Lee Gan, and Ser Zian Tan
}

\begin{abstract}
Though the world is becoming increasingly globalized, has the education evolved to prepare youth to become world citizens with the necessary skills and competencies to meet these challenges? Altogether 301 students from the Psychology and Public Relations Departments involved in community-based projects were purposively surveyed using Civic Attitudes and Competence Skills questionnaire. Results showed that overall the mean scores of the Civic Attitude and Competence Skills are moderate. The results reveal no significant difference between the Psychology students and Public Relation students in the mean scores of Civic Attitudes and Competence Skills except for subscales Civic Action, Interpersonal \& Problem-Solving Skills, Social Justice, and Diversity. The author concludes that it is important to enable youth to participate in developing a sense of self, appreciation of cultural diversity, social justice and building civic actions towards globalization awareness.
\end{abstract}

Index Terms-Civic attitudes, competence skills, diversity, social justice.

\section{INTRODUCTION}

Globalization affects every aspect of our lives and continuously provides all people of the world with major challenges, especially related to trade, technology and the environment [1]. Though the world is becoming increasingly globalized, has the education evolved to prepare youth to be global-minded citizen for this changing landscape? In today's global economy, a nation's success depends fundamentally on the knowledge, skills, and competencies of its people. This poses significant implications in preparing youths on how to become world citizens to meet these challenges. In Malaysia, much attention has been given on the importance of the development of civic attitudes and competence skills of our youths. As Bovair and Griffith [2] posited the society we now live is multicultural and multidimensional with the dilemmas of present social change. Thus, undergraduates need to develop skills and competencies such as initiatives, risk taking, strength of character and mind that may be linked to active citizenship and thereby contributes to civil society.

To address the rising international education standards, the Malaysian government has developed the Malaysia

Manuscript received June 24, 2014; August 29, 2014. This work was supported in part by the University of Tunku Abdul Rahman under UTAR Research Funds.

M. N. Lee and P. L. Gan are with the University of Tunku Abdul Rahman, Kampar Campus, Perak Malaysia (e-mail: leemn@ utar.edu.my, gplee@ utar.edu.my).

S. Z. Tan is with the Department of Comunication, Taylor's University, Kuala Lumpur, Malaysia (e-mail:tserzian@gmail.com).
Education Blueprint 2013-2025 to provide youth with necessary skills to compete in the modern workforce [3]. Six key attributes were identified by the Blueprint in order to prepare students to be globally competitive which include knowledge, thinking skills, leadership skills, bilingual proficiency, ethics and spirituality and national identity. In November 2010, Universiti Sains Malaysia, a Malaysian public university hosted "Learning to Live Together" workshop which was funded by Korea's voluntary contribution to UNESCO. A total of 50 teachers and teacher educators from Malaysia, Indonesia, Singapore, Philippines and Brunei Darussalam participated in this workshop. The workshop aimed to promote school-based initiatives on global citizenship education in line with LTLT in participating countries [4].

The positive youth development perspective is a strength-based conception of youth [5], [6] which stresses the productive capacity of young people by embracing their current potential to make substantive contributions, in return, this may increase their resilience and set a path for continued success and contributions [7]. Studies have shown that youth who are involved in PYD programmes such as positive adult-youth relationships, youth skill-building activities, and community-based activities promotes competence, confidence, character, connection, and caring for others [5], [6], [8]. Global education therefore provides opportunities for our youth to relate to each other across cultural barriers and vast distances and thus promotes deeper understanding of diverse cultures and "humanizes" people who might otherwise seem abstract [1]. The university has become a potentially vital component of the civil society locally, regionally, nationally, and internationally [9].

There is wide acceptance to embed service-learning in higher education with the aim to strengthening the acquisition of concepts while affecting students' attitudes toward social problems, community issues, and civic action [10], [11]. Similarly, community service-learning is also integrated in the undergraduate coursework [12] and the overall curriculum [13]-[15]. Studies have found positive outcomes of community service-learning with enhancement in students' skill levels in leadership, relationship building, social problem solving, occupational and life skills while fostering social and civic responsibility [16], [17].

Many studies have been conducted in various disciplines on service learning, but very few have looked into in the area of psychology with public relations, advertising and communication [18]. Little has been said about the outcomes of meaningful participation in campus activities from the positive youth development framework (positive psychology perspective) particularly in Malaysia. It is not clear to date 
how much of an impact meaningful participation has had among public relations and psychology students. The paper seeks to demonstrate the effects of meaningful participation in campus activities from a private institution in Malaysia. More specifically, it will be shown that the students' civic attitudes and competence skills have increased after participating in community-based activities run by the university.

\section{YOUTH INVOLVEMENT IN COMMUNITY-BASED SERVICE-LEARNING}

As part of the academic mission, community service learning is integrated into the academic curricula in order to instil a sense of civic responsibility and impart character development. Community service learning has been found to have positive influence in civic responsibility and life skills, increase students' critical thinking skills, improving integration of theory and practice, helping them to clarify career goals and develop skills such as team-building and interpersonal skills [13].

Community-based service-learning which was acclaimed by John Dewey as early as 1902 in the higher education emphasized the value of where thought and actions worked together in classroom and real life setting [19]. In 1970s, community-based service-learning was integrated in undergraduate programmes, specifically in public relations curriculum when advertising and public relations became popular. As noted by Giles and Eyler [19], this approach was revived in the 1990s as a result to build stronger relationships between institutions and communities with the support of funding and the need for greater institutional accountability.

Panici and Lasky [12] found that public relations courses were among the most likely to include service-learning out of the 190 universities' mass communication departments. Therefore, it is imperative that higher education institutions equipped future practitioners as strategic communicators. Most professionals believe global model of Public Relations education must be embedded in the higher education which will propel efforts toward globalization. To develop comprehensive public relations curricula, multidisciplinary approach was drawn from the experience of journalism, business, psychology, and communication professional [20]. This is integral to modern higher education.

In a nutshell, one way to strengthen civic attitudes and competence skills in young people is through community-based projects whereas students were engaged actively in the community, promote altruism and in turn increased student knowledge of the community. As reported in the study of Dugan and Komives [21], more than $53 \%$ of all college students are actively participating in community service of some kind, and more importantly the community service delivers positive outcomes on citizenship and collaboration. Similarly, Levine [22] also found that youth's civic engagement could be enhanced through participation in extracurricular groups. Yet, the question regarding on the components required for global citizenship education remain unresolved.

Other reasons for promoting community-based project is to foster the development of civic skills, leadership skills, as well as interpersonal and problem solving skills. It is indeed vital to provide meaningful opportunities for the young people to involve in civic curriculum as "it corresponds more closely to the reality the student experiences beyond the realm of school" [23]. It gets the students to be well-equipped with skills in handling issues in relevance to community and social change in order to become critical and analytical citizens. Kohut, Parker, Keeter, Doherty, and Dimock [24] report that youth today are more interested in staying abreast of national affairs and politics than the young people of the previous generation. Indeed, from the various studies reviewed, youth's meaningful involvement in social activities is a pedagogy that exposes youth to types of learning experiences that may foster positive outcome as in heightened civic attitudes [25], [26], increased political activism [24]-[26], and bonded social relationships [26], [27].

The learning and personal growth resulting from these authentic experiences connects directly to the type of tasks the students carry out, especially when the primary purpose of that task has an impact on more or more intended audiences [28]. In other words, the community-based projects help to encourage the growth of many of the cognitive factors while instilling the habit of responding to community needs in socially constructed ways. In a nutshell, it is therefore important to provide youth with a systematic approach for examining their individual abilities, interests and explore areas of potential involvement based on their existing or developing interests.

Specifically, for the case of Universiti Tunku Abdul Rahman, Malaysia, the Department of Public Relations started the first on campus campaign in the university in 2010. A year later, the department expanded its collaboration with local town council, non-profits and communities by setting up a new village library in Tronoh Mines New Village, Perak, Malaysia. The Public Relations Campaign Planning and Management course aims to provide students with hands-on experience in planning and execution of public relations campaign. For a period of 4-month, students will engage in different campaigns advocating different issues affecting the local communities. In addition, campaigns allow students to be critical thinkers in proposing effective and creative solutions to the local communities, and at the same time creating aspirations towards global citizenship. This course provides an ideal service-learning environment in which community service and volunteerism are integrated.

PR campaign is a compulsory requirement for graduation and is in-line with the University's vision to become "a global university of educational excellence with transformative societal impact" as the university was created through the contribution made by many people [29]. This allows the production of responsible citizen who are active in their communities, providing solutions and mutual support for each other.

Therefore, this study undertakes to study on students' civic attitudes and competence skills that were involved in various community-based projects, uses the service-learning approach in a private university. As students from the Public Relations and Psychology Departments were selected for this research, the study would like to examine whether there is any difference in their civic attitudes and competence skills measured by course level. 


\section{Methodology}

Using cross-sectional survey design and purposive sampling, a total of 301 undergraduates enrolled in the public relations and psychology course at a private university were surveyed on their perception of civic attitudes and competence skills to measure the positive outcomes as a result of youth's meaningful participation in their campus/school activities.

The Public relations students were involved in wide range of community-based projects working closely with non-profit organizations, local government, schools in projects related to health, education, culture and arts, indigenous people, green environment and protection on animals. Some activities which were carried out include building a local library, refurnishing school and canteen, teaching primary school children of the indigenous people, and raising funds for charitable organization. On the other hand, the Psychology students were mainly involved in various community service-projects such as helping in welfare homes orphanages, recycling activities, and teaching little children in kindergartens as part of their assignment projects.

The Civic Attitudes and Skills Questionnaire (CASQ), developed by Moely, McFarland, Miron, Mercer and Ilustre [26] yields scores on six scales which measure civic action, political awareness, leadership skills, social justice attitudes, diversity attitudes, and interpersonal and problem-solving skills. Reliability for the total scale yielded a cronbach alpha value of .88 for the pre-test and .89 for the post-test done by Khoo, Lim and Liau [30]. The result was better than the internal consistencies range from .69 to .88 reported by Moely, McFarland, Miron, Mercer and Ilustre [26] on the psychometric properties and correlates of the Civic Attitudes and Skills Measure.

\section{FINDINGS AND DisCUSSION}

Results showed that the mean of all the mean scores were above the mid-point of 3.00 with the total mean score of Civic Attitudes and Competence Skills as 3.49 with a standard deviation of .26. The mean scores of the Civic Attitude $(M=3.46, S D=.30)$ and Competence Skills $(M=$ $3.53, S D=.26)$ were considered slightly above moderate level. Among the subscales in Civic Attitudes, the respondents appeared to obtain the highest mean scores for Civic Action $(M=3.76, S D=.44)$ as a whole. The result suggests that generally the respondents perceived that they would most likely plan to be involved in future civic participation from their meaningful participation in campus activities.

On the other hand, the mean scores was slightly lower for political awareness $(M=3.23, S D=.52)$ as compared to social justice $(M=3.63, S D=.39)$ subscale. The findings seems to suggest the generally the youths were keener in understanding the social situation of the surroundings rather than knowing the political affairs of the countries. Among the subscales in Competence Skills, the respondents appeared to obtain the highest mean scores for Interpersonal and Problem-Solving Skills $(M=3.72, S D=.35)$ as a whole. The result suggests that the respondents seemed to gain more in terms of personal and problem-solving skills from their meaningful participation in the campus activities. The finding is somewhat consistent with Liou [23] and Lee [31] who indicated that group activities, such as Public Relations campaigns and community-service projects, may be fertile ground for youth development skills. The myriad of group activities may significantly contribute to young people's leadership and character-building.

The independent samples $t$-test was conducted to compare the means for the civic attitudes and competence skills measures between respondents of different course level as in Table I.

TABLE I: COMPARISON OF CIVIC ATTITUDES AND COMPETENCE SKILLS BY COURSE WORK $(N=301)$

\begin{tabular}{lllll}
\hline \hline Scale/Subscale & PY Group & $\begin{array}{l}\text { PR } \\
\text { Group }\end{array}$ & $t$-value & $p$-value \\
\hline Civic Attitudes & $\mathbf{3 . 4 6}$ & $\mathbf{3 . 4 6}$ & $\mathbf{. 0 7}$ & $\mathbf{. 9 4}$ \\
Civic Action & 3.82 & 3.69 & 2.67 & $.01^{* *}$ \\
Political & 3.24 & 3.21 & .58 & .56 \\
Awareness & 3.33 & 3.42 & -1.97 & $.05^{*}$ \\
Social Justice & 3.33 & 3.44 & -2.38 & $.02^{*}$ \\
Diversity Attitude & & & & \\
Competence & & & & \\
Skills & $\mathbf{3 . 5 5}$ & $\mathbf{3 . 5 1}$ & $\mathbf{1 . 4 4}$ & $\mathbf{. 1 5}$ \\
Interpersonal \& & & & & \\
Problem-Solving & 3.79 & 3.68 & 2.71 & $.01^{* *}$ \\
Skills & 3.26 & 3.22 & .83 & .41 \\
Leadership Skills & 3.44 & 3.46 & -.61 & .54 \\
Sensitivity & & & & \\
\hline \hline
\end{tabular}

Results show that there were no significant differences in the mean scores between the Public Relations and the Psychology students at the .05 level for the mean scores, except Civic Action, Social Justice, Diversity Attitude, and Interpersonal and Problem Solving subscales. The results indicate that Civic Attitudes and Competence Skills and course level were statistically independent variables. In other words, the results suggest that the Public Relations and Psychology respondents do not differ significantly in the overall civic attitude and competence skills.

However, the means scores in Civic Action was significantly higher for the Psychology students $(M=3.82$, $S D=.46)$ as compared to the Public Relations students $(M=$ $3.69, S D=.41)$ where $t(229)$ at $p<.01$. The means scores in Interpersonal and Problem-Solving was significantly and slightly higher for the Psychology students $(M=3.79, S D$ $=.35)$ as compared to the Public Relations students $(M=3.68$, $S D=.35)$ where $t(229)$ at $p<.01$. On the other hand, the mean scores for Diversity Attitude $(M=3.44, S D=.33)$ and Social Justice $(M=3.42, S D=.32)$ were significantly and slightly higher for the Public Relations respondents at $p<.05$ as compared to the Psychology students.

The results seem to suggest that the Psychology students were slightly more willing to participate and involved in community service than the Public Relations students. The Psychology students seem to be better in their ability to listen, work cooperatively and communicate with others, to lead as well as to think logically and solve problems than the Public Relations students. The finding is consistent with Lee [31] who contended that as student leaders learn to consider how they act and react to what happens around them, they are encouraged to act as examples for others in the team. In her study, Lee [31] found that program leaders had used their 
creativity and facilitation skills to nurture youth participants on leadership in the programme. The programme had also influenced youths' learning and personal growth as well as building relationships with others.

On the other hand, the results seem to suggest that the Public Relations respondents were slightly more concern about social issues such as poverty, illiteracy, public policy and social injustice than the psychology respondents. The findings are somewhat consistent with the findings of Lattimore, et al. [20], Liou [23] and Ibrahim [32]. Silverman [33] also reported that students who are involved in public relations campaign course were civic oriented and responsible in community problem and learnt important public relations campaign skills. In fact, one of the most significant contributions of the Public Relations students was raising a total of RM 40,000 funds for National Kidney Foundation in 2012 [29]. This gives young people the opportunities to become engaged in civic activities which will likely increase the likelihood of them becoming active citizens.

In other words, as a result of the community-based project experience, as a whole, the respondents seem to show a moderately high level of development of civic attitudes and competence skills. The respondents seem to reflect some changes in attitudes toward diversity and social issues, and even had plans for future civic action. Larson [34] describes it as youths' development of initiative, which is closely related to capacity for agency or for autonomous action. Through the community-based projects, youths seem quite motivated from within to direct attention and effort towards personal competencies and at the same time may likely to engage in some form of civic responsibilities. While some respondents seem to achieve more personal benefits, other respondents seem to gain an understanding far more than just themselves, that is, to help others. The findings are in line with Terry, Bohnenberger, Renzulli, Cramond, and Sisk [28] who posit that community-based projects may gear youths towards global learning whereby youths are engaged in decision-making, practice prosocial action, view situations from multiple perspectives, use conflict-resolutions, and have opportunities to deal with social injustice. The findings are also consistent with Theokas and Bloch [35] who report that there is a relationship between youth's volunteerism and several individual variables linked to the Cs of PYD, namely, doing better in school (Competence), feeling more positive about the self (Confidence), avoidance of drug-use (Character), and likelihood of being socially responsible (Contribution).

In a nutshell, educators need to provide meaningful opportunities for students to actively participate in community-based projects related to global education. Learning opportunities include provision to experience positive relationships through supportive and caring interpersonal interactions, as well as provision to experience new ways of being. Opportunities for participation in the community-based projects and contribution to the community at large may provide meaningful responsibilities, real decision-making power, a sense of ownership and belonging, and ultimately a sense of purpose and belief in future. Thus, given a nurturing environment that taps into youth strengths, all youths may have an innate capacity for change and transformation. The community-based projects in the university ground are one such programme to build on youth capacity and competency. Students' experiences of citizenship within the campus and local community influence their commitment to values of "social justice and equity" and "respect for diversity' as global citizens. In the context of global interdependence, there is a need to develop a vision of global education that encourages critical understanding of and respect for human rights and responsibilities [28], [31], [33].

\section{CONCLUSION}

Very limited studies have explored positive outcomes as in civic attitudes and competence skills as a result of meaningful participation in campus activities from the positive youth development framework (positive psychology perspective) particularly in Malaysia. Thus, in an effort to fill in the gaps in the literature, the study seeks to identify the quantitative analysis of the relationship between youth's civic attitudes and competence skills and to identify whether there is course level difference in the civic attitudes and competence skills as a result of their perceived meaningful participation experience.

As Ibrahim [33] suggests, global education is based on the principals of respect for human rights and cultural diversity, democracy and tolerance, and is characterized by pedagogical approaches based on human concern for social justice which encourage critical thinking and responsible participation. In other words, global education curricular require the creation of a set of conditions that demand the integration of a number of processes and attributes along with the use of technology to facilitate global connections to educate our youth to become future world citizen[28]. Thus, one can see that youth actualization of these elements is dependent on acquisition of the global-learning attributes and processes discussed earlier in this paper.

Higher institutions need not only design and implement learning opportunities for youth within the classroom but also need to identify learning resources and opportunities in the community that are integrated with those of classroom [28], [31]. Community-based projects can offer such opportunities for our youth to analyze the situation, generate new ideas, and work as a team to implement a difference-making plan of action. In the process, the students develop complex problem-solving skills and advanced communication skills; they also develop the ability to connect knowledge across disciplines and the perseverance to overcome obstacles.

Therefore, in line with current education curriculum with its emphasis on character development, this study may add significance to the importance of extracurricular/ after-school programmes in youth development. The study may give preventionists the asset-based language needed to mirror youth's civic attitudes and competency through meaningful participation. Future researchers, educators or health practitioners may study positive development in youth or develop preventive intervention programmes in order to build capacity, skills and competency in youth.

\section{REFERENCES}

[1] S. Chen, B. Mulgrew, and P. M. Grant, "A clustering technique for digital communications channel equalization using radial basis 
function networks," IEEE Trans. on Neural Networks, vol. 4, pp. 570-578, July 1993.

[2] K. L. Gibson, G. M. Rimmington, and M. L. Brown, "Developing global awareness and responsible world citizenship with global learning," Roeper Review, vol. 30, pp. 11-23, April 2008.

[3] K. Bovair and R. Griffith, "Global citizenship: from concept to classroom," Support for Learning, vol. 18, no. 3, pp. 107-111, July 2003.

[4] Preliminary report: Malaysia Education Blueprint. 2013-2015. (2003) [Online]. Available: http://www.moe.gov.my/userfiles/file/PPP/Preliminary-Blueprint-Eng .pdf

[5] Global citizenship education for a culture of peace an sustainable future. [Online]. Available: http://www.unescobbk.org/education/teacher-education-and-training/ global-citizenship-education-for-a-culture-of-peace-and-sustainable-f uture/

[6] R. M. Lerner, J. B. Almergi, C. Theokas, and J. V. Lerner, "Positive youth development: a view of issues," Journal of Early Adolescene, vol. 25 , no. 1 , pp. 10-16, 2005.

[7] J. L. Roth and J. B. Gunn, "What exactly is a youth development program? Answers from research and practice," Applied Developmental Science, vol. 7, no. 2, pp. 94-111, 2003.

[8] W. Damon, "What is positive youth development?" The ANNALS of the American Academy of Political and Social Science, vol. 591, pp. 13-24, January 2004.

[9] A. M. McBride, E. Johnson, R. Olate, and K. O'Hara, "Youth volunteer service as positive youth development in Latin America and the Caribbean," Children and Youth Services Review, vol. 33, pp. 34-41, January 2011.

[10] R. Ennals, L. Stratton, N. Moujahid, and S. Kovela, "Global information technology and global citizenship education," Springer-Verlag London Limited, vol. 23, pp. 61-68, Jan. 2009.

[11] J. Eyler and D. E. Giles, "Where's the learning in service-learning?" Jossey-Bass Higher and Adult Education Series, Jpssey-Bass Inc., CA: San Francisco, 1999.

[12] H. Reinders and J. Youniss, "School-based required community service and civic development in adolescents," Applied Developmental Science, vol. 10, no. 1, pp. 2-12, 2006.

[13] D. Panici and K. Lasky, "Service learning's foothold in communication scholarship," Journalism \& Mass Communication Educator, vol. 57, no. 2, pp. 113-125, 2002.

[14] K. P. Werder and K. Strand, "Measuring student outcomes: an assessment of service learning in the public relations campaign course," Public Relations Review, vol. 37, no. 2, pp. 478-484, Dec. 2011.

[15] S. A. Patterson, "How service-learning enhances your PR program," Public Relations Tactics, vol. 11, no. 4, pp. 23, 2004.

[16] D. F. Witmer, D. A. Silverman, and D. J. Gaschen, "Working to learn and learning to work: a profile of service-learning courses in university public relations programs," Public Relations Review, vol. 35, pp. 153-155, June 2009

[17] A. M. McCarthy and M. Tucker, "Student attitudes towards service learning: Implications for implementation," Journal of Management Education, vol. 23, pp. 554-573, October 1999.

[18] J. S. Pariola and A. G. Pariola, "Expanding the parameters of service learning: A case study," Journal of Studies in International Education, vol. 10, pp. 71-86, Spring 2006

[19] E. Akpabio. (2012). Beneficiaries' perspective on service learning: Case study of advertising and public relations campaign course. Sage Open. [Online]. pp. 1-7. Available: http://sgo.sagepub.com/content/2/3/2158244012460694.full-text.pdf+ html

[20] N. Muturi, S. An, and S. Mwangi, "Students' expectations and motivation for service-learning in public relations," Journalism \& Mass Communication Educator, vol. 68, no. 4, pp. 387-408, Oct. 2013.

[21] D. Lattimore, O. Baskin, S. Heiman, and E. L. Toth, Public Relations the Profession and the Practice, $3^{\text {rd }}$ ed., Singapore: McGraw Hill, 2009.

[22] J. P. Dugan and S. R. Komives, "Developing leadership capacity in college students: findings from a national study, a report from the multi-institutional study of leadership," College Park, MD: National Clearinghouse for Leadership Programs, 2007.

[23] P. Levine, "A public voice for youth: the audience problem in digital media and civic education," in Civic Life Online Learning How Digital Media Can Engage Youth, The MIT Press, MA: Cambridge, 2008, pp. 119-138.

[24] S. M. Liou, "The effect of we the people...project citizen on the civic skills and dispositions of Taiwanese senior high school students," Journal of Taiwan Normal University, vol. 49, no. 1, pp. 63-90, April 2003.
[25] A. Kohut, K. Parker, S. Keeter, C. Doherty, and M. Dimock, "How young people view their lives futures and politics," A Portrait of Generation Next, Washington DC: Pew Research Center, 2007.

[26] A. W. Austin and L. J. Sax, "How undergraduates are affected by service participation," Journal of College Student Development, vol 39, no. 2, pp. 251-263, 1998.

[27] B. E. Moely, M. Farland, D. Miron, S. Mercer, and V. Ilustre, "Changes in college students' attitudes and intentions for civic involvement as a function of service-learning experiences," Michigan Journal of Community Service Learning, vol. 9, no. 1, pp. 18-26, 2002.

[28] K. G. McKinney, "Engagement in community service among college students: is it affected by significant attachment relationships?' Journal of Adolescence, vol. 25, no. 1, pp. 139-154. 2002.

[29] A. W. Terry, J. E. Bohnenberger, J. S. Renzulli, B. Cramond, and D Sisk, "From vision with action: developing sensitivity to societal concems in Gifted Youth," Roeper Review, vol. 30, pp. 61-67, April 2008.

[30] UTAR PR Students Contribute to UTAR Education Foundation. [Online]

Available: http://www.utar.edu.my/contentPageNewsAwards.jsp?\&YearArchive $=2012 \&$ catid $=16 \&$ contentid $=3053$

[31] A. Khoo, K. M. Lim, and A. Liau, "The SIF/YEP study: a summary of findings," Unpublished report, National Youth Council, Singapore 2004.

[32] M. N. Lee, "Resilience and positive youth development in youth: Overseas community service-learning experience," unpublished, Ph.D. dissertation, Nanyang Technological University, Singapore, 2007.

[33] T. Ibrahim, "Global citizenship education: mainstreaming the?" UK Cambridge Journal of Education, vol. 35, no. 2, pp. 177-194, June 2005.

[34] D. A. Silverman, "Organ donation awareness campaigns in a PR campaign course," Journalism and Mass Communication Educator vol. 61, pp. 411-429, 2007.

[35] R. W. Larson, "Towards a psychology of positive youth development," American Psychologist, vol. 55, no. 1, pp. 170-183, 2000.

[36] C. Theokas and M. Bloch, "Out of school time is critical for children: who participates in program?" Child Trends, Washington D.C, 2006.

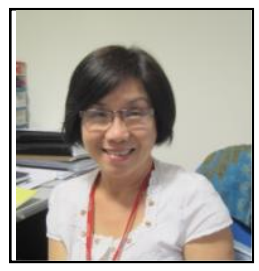

Mah Ngee Lee was born in B. Perak, Malaysia, She graduated with B.A. (Hons) in English and Malay studies, University of Malaya (UM), Kuala Lumpur, Malaysia, 1987; M.Ed. in educational psychology, Malaysia Science University (USM), Penang, Malaysia, 2000; and PhD in psychological studies, University Technological University (NTU), Singapore, 2007.

She is currently an assistant professor in the Department of Psychology \& Counselling, Faculty of Arts \& Social Science, Kampar Campus, UTAR. In 2003, she became a full-time research student (with three-and-half-year scholarship) and lecturer at the psychological studies academic group in National Institute of Education, Nanyang Technological University, Singapore. Lee was appointed as deputy dean in charge of academic development and undergraduate programmes for Faculty of Arts and Social Science, UTAR in 2011. Lee has published two book-chapters, firstly, "Youth expedition programming in Singapore: Building resilience and positive personal development" in L. Liebenberg \& M. Ungar (Eds.), resilience in action: working with youth across cultures and contexts (pp. 238-263) published by University of Toronto Press Incorporated, Canada, and secondly "Building youth capacities and civic values through oversea community service experience" in Goh, K.C., 'Rozario, V., Ch'ng, T.H. A. \& Cheah, H.M. (2009), character development through service experiential learning. (pp. 140-153) by Prentice Hall Singapore.

Dr. Lee's research interests include resilience, youth issues, community service-learning, positive psychology, and educational psychology. Dr. Lee is also one of the recipients of the 2014 Taiwan fellowship program, currently conducting a research on meaningful engagement in activities and happiness in youth.

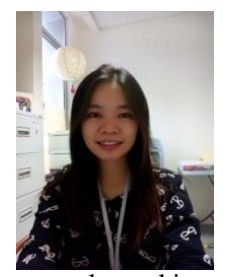

Pei Lee Gan graduated with first class honours in bachelor of communication (Hons) public relations in 2006 from Universiti Tunku Abdul Rahman (UTAR), Petaling Jaya Campus, Malaysia. She received a scholarship from professor Yang Fujia to pursue her master degree in University of Nottingham, Ningbo, China. She graduated with master of arts in international communication in 2008 and is now currently working as full-time lecturer in Department of Public Relations and 
currently working as full-time lecturer in Department of Public Relations and also deputy dean in-charge of student development and industrial training for Faculty of Arts \& Social Science, Kampar Campus, UTAR.

She was appointed as the head of Department for Public Relations Department in 2011 and later in 2013 appointed as deputy dean. In 2012, she received UTAR's staff scholarship to pursue doctor of philosophy (social science). She later became a member of centre for applied psychology and worked closely with Dr. Lee Mah Ngee in developing research related to positive youth development. Ms Gan together with principal researcher, Dr. Lee Mah Ngee and co-researcher Ms Tan Ser Zian received UTAR's research grant in 2012 to conduct a research on "Youth's perspective on meaningful participation and their positive outcomes on personal development". Her papers have been accepted in international conference of business, accounting, finance and economics in 2013 and $2^{\text {nd }}$ international conference on behavioural \& social science research 2014. Her areas of research include social media and positive youth development.

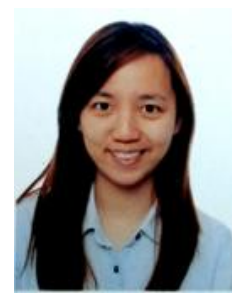

Ser Zian Tan was born in B. Kuala Lumpur, Malaysia, She graduated with B.A.(Hons) Advertising, University of Tunku Abdul Rahman (UTAR), Selangor D. E., Malaysia, 2008; M.A. in International Communication, Nottingham University, Ningbo, China, 2009. She is currently a lecturer in the School of Communication, Taylor's University, Selangor D. E., Malaysia as well as a part-time $\mathrm{PhD}$ student in Business at Monash University, Malaysia.

Tan started her teaching career at University of Tunku Abdul Rahman, Kampar, Malaysia for 5 years before she joined Taylor's University in 2014 In addition to teaching, she devotes her passion in research and her areas of study include consumer behaviour, new media effects, gender studies, positive youth development, e-learning and advertising impacts. 